\title{
Short Communication Nitrooxyethylation Reverses the Healing-Suppressant Effect of Ibuprofen
}

\author{
Mandeep Kaushal, ${ }^{1}$ N. Gopalan Kutty, ${ }^{2}$ and C. Mallikarjuna Rao ${ }^{2}$ \\ ${ }^{1}$ Panacea Biotec Ltd, Mohan Cooperative Industrial Estate, New Delhi 110044, India \\ ${ }^{2}$ Department of Pharmacology, Manipal College of Pharmaceutical Sciences, Manipal Academy of Higher Education, \\ Manipal 576 104, India
}

Received 23 January 2006; Revised 30 March 2006; Accepted 30 March 2006

\begin{abstract}
Nonsteroidal antiinflammatory drugs like ibuprofen impede tissue repair by virtue of retarding inflammation. The present study was undertaken to explore if linking of nitrooxyethyl ester to ibuprofen reverses its healing-depressant propensity. Nitrooxyethyl ester of ibuprofen (NOE-Ibu) was synthesized in our laboratory through a well-established synthetic pathway. NOE-Ibu was screened for its influence on collagenation, wound contraction and epithelialization phases of healing, and scar size of healed wound in three wound models, namely, incision, dead space, and excision wounds. Besides, its influence on the oxidative stress (levels of GSH and TBARS) was also determined in 10-day-old granulation tissue. NOE-Ibu was further screened for its antiinflammatory activity in rat paw edema model. NOE-Ibu promoted collagenation (increase in breaking strength, granulation weight, and collagen content), wound contraction and epithelialization phases of healing. NOE-Ibu also showed a significant antioxidant effect in 10-day-old granulation tissue as compared to ibuprofen. Results vindicate that the esterification of ibuprofen with nitrooxyethyl group reverses the healing-suppressant effect of ibuprofen. The compound also showed equipotent antiinflammatory activity as ibuprofen.
\end{abstract}

Copyright ( $) 2006$ Mandeep Kaushal et al. This is an open access article distributed under the Creative Commons Attribution License, which permits unrestricted use, distribution, and reproduction in any medium, provided the original work is properly cited.

\section{INTRODUCTION}

Wound repair is the effort of tissues to restore normal function and structure after injury. In the initial stages, it involves reformation of barriers to fluid loss and infection besides limiting further entry to foreign organisms and material. Eventually, wound healing reestablishes normal blood and lymphatic flow patterns and restores mechanical integrity of the injured system. Normal wound healing follows a predictable pattern that can be divided into overlapping phases defined by cellular populations and biochemical activities: (a) hemostasis and inflammation, (b) proliferation, and (c) maturation and remodeling.

Antiinflammatory agents whose principal effect is to diminish granulocytic inflammatory reaction also have healing-depressant propensity [1]. Nonsteroidal antiinflammatory drugs that decrease breaking strength in incision wounds were found to have variable effects on wound contraction, and epithelialization $[2,3]$. Ibuprofen was reported to reduce the breaking strength of the repaired extensor tendon, wound contraction, and epithelialization [4-6]. Nitric Oxide (NO) is a labile intercellular messenger molecule regulating a range of physiological functions that includes vascular tone, platelet aggregation, the immune response, and neurotransmission in brain as well as in periphery [7]. $\mathrm{NO}$ is also involved in pathogenesis of acute and chronic inflammatory conditions. Mast cells, which release a number of mediators like histamine and 5-hydroxytryptamine, also produce NO [8]. Exogenous NO can however modulate mast cells degranulation, which could therefore act as a feedback inhibitor $[9,10]$. Findings from rat model of edema evoked by carrageenan suggest that e-NOS is involved in the development of this acute inflammatory response, whereas iNOS is involved in maintenance of the inflammatory response [11-13]. NO has been reported to be involved in the angiogenic mechanisms of activated macrophages since inhibitors of NOS cause an inhibition of macrophage-dependent angiogenesis [14].

The nitric oxide (NO) donating compound, isosorbide5 -mononitrate, has been found to reverse the mucosal damaging effect of castor oil $[15,16]$. Inhibitors of NO exerbate the gastric mucosal injury caused by indomethacin. The conversion of some acidic NSAIDs like flubriprofen to their nitrooxyethyl esters has resulted in reduction in gastric 
ulcerogenicity without any concomitant decrease in antiinflammatory activity [17].

Since inflammation is a prelude to wound healing and $\mathrm{NO}$ is a mediator in inflammation and a potent angiogenic factor $[14,16,18,19]$, the present work was planned to see if linking of an NO donor to ibuprofen could reverse the latter's influence on healing, yet retaining its original antiinflammatory effect. So the study was carried out to compare the effects of nitrooxyethyl ester of ibuprofen (NOE-Ibu) with respect to its parent molecule (Ibu) on different wound models and to appraise its effects on an acute inflammatory model.

\section{MATERIAL AND METHODS}

\section{Reagents and chemicals}

Ibuprofen [(RS)-2-(4-isobutylphenyl) propionic acid] was purchased from Arora Pharmaceuticals (Delhi, India). Benzene, P-toluene sulphonic acid, silica gel, n-propanol, and sodium sulphate were obtained from Qualigens Fine Chemicals (Mumbai, India). Reduced glutathione (GSH) and hydroxyproline (OHP) were purchased from Sigma Aldrich (Bangalore, India). Nitrooxyethyl ester of ibuprofen (NOEIbu) $\left(\mathrm{C}_{15} \mathrm{H}_{21} \mathrm{~N}_{1} \mathrm{O}_{5}\right)$ was synthesized in our laboratory through a well-established synthetic pathway and its structure was established through analytical and spectral data.

\section{Animals}

Healthy inbred male albino rats of Wistar strain weighing between $180 \mathrm{~g}$ and $200 \mathrm{~g}$ were used for the study. They were individually housed in sterile polypropylene cages and maintained on normal food and water adlibitum. No external or internal chemotherapeutic cover was provided to the animals except the drugs under test. The surgical interventions were carried out under ketamine anaesthesia $(10 \mathrm{mg} / \mathrm{kg})$. All experimental procedures were carried out in accordance with the guidelines of Institutional Animal Ethics Committee.

\section{Drug and dosing}

Animals were divided into three groups each having eight animals. While control group received $4 \%$ suspension of gum Acacia, the second and third groups received ibuprofen (in the dose of $200 \mathrm{mg} / \mathrm{kg}$ ) and NOE-Ibu (300 mg/kg), respectively. The drug solutions that were suspended using a $4 \%$ gum Acacia and the vehicle were administered in the volume of $5 \mathrm{~mL} / \mathrm{kg}$. The dose of Ibu was arrived at by computing the minimum human dose to rat based on the surface area. The dose of NOE-Ibu contained equal amount of Ibu that was given to group two animals.

\section{Incision wound model}

This model was employed to determine the breaking strength of incision wound in rats as per the methods described by
Ehrlich et al [20-22]. Two paravertabral straight-line incisions were made on either side of the vertebral column on the shaven back of the animals. Wounds were closed with intermittent sutures of $1 \mathrm{~cm}$ apart. Animals were treated daily with drugs from 0th to 9th postwounding day. Sutures were removed on 7th postwounding day and wound breaking strength was estimated on 10th postwounding day by constant water flow technique as described by Lee [1].

\section{Excision wound model}

The parameters such as wound contraction, epithelialization, scar size, and histopathology were monitored in this wound model. Using Accupunch of $10 \mathrm{~mm}$ diameter, a full-thickness skin was excised to get a wound measuring $79 \mathrm{~mm} \mathrm{[2]} \mathrm{in} \mathrm{the}$ fur clipped dorsal thoracic central region, $5 \mathrm{~cm}$ away from the ears of anaesthetized rats. After achieving full hemostasis, animals were placed in their individual cages. Animals received drugs daily from 0th day to 21 st postwounding day or until the healing was complete, whichever was earlier.

\section{Wound contraction}

The wound contraction was calculated as percentage of the original wound size (79 mm [2]) for each animal of a group and group mean was calculated on predetermined days, namely, days $4,6,8,10,12,14$, and 16 for final analysis of results.

\section{Period of epithelialization}

Falling of scab, leaving no raw wound behind, was taken as the endpoint of complete epithelialization and the days required for this were taken as the period of epithelialization.

\section{Scar area}

Scar area was measured by tracing the intact healed wound area on tracing paper on the final day when there seemed to be no visible change in the wound area and the wound had completely healed and closed.

\section{Histopathological evaluation}

On day 10, a small piece of the intact healed wound with edges was excised from an animal of each group and fixed in $10 \%$ neutral buffered formalin. Histopathological evaluation was carried using Hematoxylin \& Eosin (H \& E) stained 5-6 $\mu$ thin paraffin longitudinal sections.

\section{Dead space wound model}

This method is usually employed for assessing the extent of collagenation. The dead space wound was created by implanting subcutaneous $2.5 \times 0.5 \mathrm{~cm}$ polypropylene 
tubes of two numbers in the lumbar region on dorsal side [23]. Animals received drugs from 0th day to 9th postwounding day. On 10th postwounding day, granulation tissue harvested on each implanted tube was carefully dissected out along with the tube and employed for determination of breaking strength. While one tubegranulation was used for the estimation of hydroxyproline (OHP), the other tubegranulation was used to determine the levels of reduced glutathione (GSH) and thiobarbituric acid reactive species (TBARS).

\section{Determination of breaking strength of granulation \\ tissue}

A piece of granulation tissue was fixed between two Babcock forceps and its breaking strength was measured by a constant and continuous water flow technique.

\section{Determination of dry granulation weight}

The granulation tissue was collected and dried at $60^{\circ} \mathrm{C}$ for 24 hours to get constant weight and was weighed.

\section{Estimation of hydroxyproline}

The dry granulation tissues were digested using $6 \mathrm{~N} \mathrm{HCl}$ and the neutral hydrolysate was used to estimate the content of hydroxyproline by the method of Neuman and Logan (1950) (see [24]).

\section{Estimation of reduced glutathione (GSH)}

GSH contents were determined in the granulation tissue by the method of Okhawa et al [27].

\section{Estimation of thiobarbituric acid reactive substances}

Malonialdehyde formed from the breakdown of polyunsaturated fatty acids serves as a convenient index for determining the extent of peroxidation reaction. Malondialdehyde is the product of lipid peroxidation that reacts with thiobarbituric acid to give red species absorbing at $535 \mathrm{~nm}$ [26].

\section{Carrageenin-induced rat paw edema}

The method of Winter et al (1962) was used with slight modifications. Rats were dosed orally with NOE-Ibu and ibuprofen drugs at calculated doses. One hour after drug administration, subplantar injection of $0.05 \mathrm{~mL}$ of $1 \%$ suspension of carrageenan was performed. The paw volumes, immediately after injection (0th hours volume) and 3 hours after injection (3rd hour volume), were measured using plethysmograph. The difference between the 0th hour paw volume and 3rd hour paw volume gave edema volume, which was further used to calculate percentage of inhibition.

\section{Statistical analysis}

One-way ANOVA followed by Scheffe's post hoc test using SPSS computer package analyzed results.

\section{RESULTS}

\section{Breaking strength of 10-day-old incision and dead space wounds}

Breaking strengths of 10-day-old incision and dead space wounds in the control group of animals were $357 \mathrm{~g}$ and $271 \mathrm{~g}$, respectively. Ibuprofen significantly $(P<.05)$ reduced the strengths of the scars of incision and the granulation tissues of the dead space wounds as compared to that of control group. On the other hand, nitrooxyethyl ester of ibuprofen significantly promoted the strengths of the healed wounds as compared to Ibuprofen and control. It is clear from the findings that ibuprofen depressed breaking strength while nitrooxyethyl ester of ibuprofen did not do this. In fact, it increased the breaking strength of incision wound (Figure 1 and Table 1).

\section{Biochemical attributes of granulation tissues of dead space wounds}

\section{(i) Collagen content}

The concentration of hydroxyproline (a marker of collagen content) present in 10-day-old granulation tissue (dead space wound) in control group of animals was $27.5 \mathrm{mg} / \mathrm{g}$, while it was $13.3 \mathrm{mg} / \mathrm{g}$ in ibuprofen-treated group (a significant $P<.05$ reduction compared to control). On the other hand, the collagen content in nitrooxyethyl ester of ibuprofen-treated animals was found to be $43.4 \mathrm{mg} / \mathrm{g}$, which was significantly $(P<.05)$ more than that of ibuprofen as well as control group of animals values. A trend similar to that seen in the changes of collagen content in different groups of animals was seen in the dry granulation weights as well (Table 2).

\section{(ii) Oxidative stress parameters}

The levels of thiobarbituric acid reactive substance (TBARS) in granulation tissue of control group animals was 3.98 $\mu \mathrm{M} / \mathrm{g}$. This was significantly $(P<.05)$ increased with the treatment of ibuprofen to an extent of four folds. This indicated an oxidative stress induction with ibuprofen (Table 1). However, it increased the levels of reduced glutathione (GSH) significantly $(P<.05)$ as compared to control. Nitrooxyethyl ester ibuprofen, on the other hand, reduced the level of TBARS as compared to that of parent compound and the control group. Further, it increased the levels of GSH significantly $(P<.05)$ more than that of the parent compound and the control group (Table 2 ). 


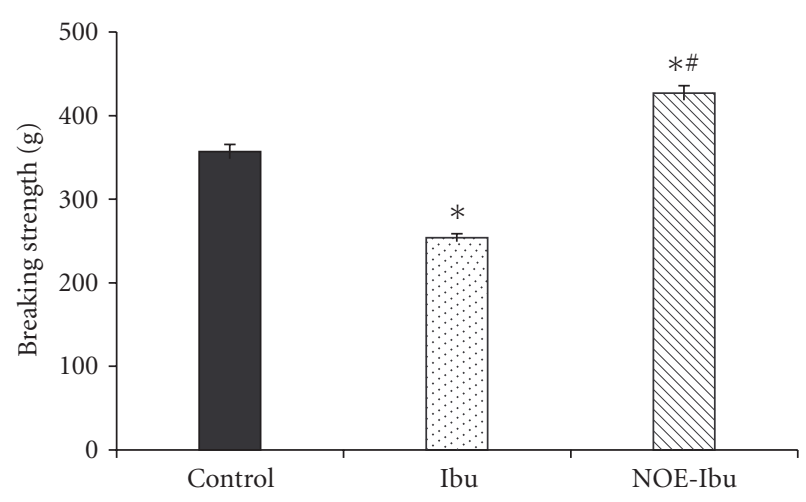

FIGURE 1: Effect of drugs on breaking strength of 10-day-old incision wound. Each bar represents mean \pm SEM. Control animals were administered 4\% suspension of gum Acacia at dose $5 \mathrm{~mL} / \mathrm{kg}$, Ibu group received $200 \mathrm{mg} / \mathrm{kg}$ of ibuprofen and NOE-Ibu received $300 \mathrm{mg} / \mathrm{kg}$ nitrooxyethyl ester of ibuprofen. Mean value of 8 animals gave the breaking strength of the given group.

TABLE 1: Wound models employed and parameters monitored.

\begin{tabular}{|c|c|c|c|}
\hline Wound model & Drug treatment & Parameter monitored & Remarks \\
\hline $\begin{array}{l}\text { Incision wound } \\
\text { (for collagenation phase) }\end{array}$ & $\begin{array}{l}\text { From 0th-9th } \\
\text { postwounding } \\
\text { day }\end{array}$ & Breaking strength & $\begin{array}{l}\text { Suture removed on the } 7 \text { th postwounding day, } \\
\text { breaking strength measurement on the 10th } \\
\text { postwounding day }\end{array}$ \\
\hline $\begin{array}{l}\text { Excision wound } \\
\text { (for the wound contraction, } \\
\text { epithelialization and scar size) }\end{array}$ & $\begin{array}{l}\text { From 0th-21st } \\
\text { postwounding day }\end{array}$ & $\begin{array}{l}\text { Wound contraction, period of } \\
\text { epithelialization, scar size, } \\
\text { histopathology of } \\
\text { granulation tissue }\end{array}$ & $\begin{array}{l}\text { Measured as \% of the original wound size, } \\
\text { calculated as number of days taken for the fall } \\
\text { of scab with no raw wound remaining, } \\
\text { scar area on the day of completed healing }\end{array}$ \\
\hline Dead space wound & $\begin{array}{l}\text { From 0th-9th } \\
\text { postwounding day }\end{array}$ & $\begin{array}{l}\text { Granulation breaking } \\
\text { strength, dry granulation } \\
\text { weight, hydroxyproline } \\
\text { estimation and antioxidation } \\
\text { studies in the granulation } \\
\text { tissue (GSH and TBARS) }\end{array}$ & $\begin{array}{l}\text { Parameters measured on the day } 10 \\
\text { postwounding }\end{array}$ \\
\hline
\end{tabular}

\section{Wound contraction of excision wound}

The rate of wound contraction in the animals that received vehicle (control) was $26 \%, 71 \%$, and $90 \%$, respectively, by day 4 , day 8 , and day 12 . However, the wound contraction was significantly $(P<.05)$ low in animals that received ibuprofen as compared to control. This was reversed by NOE-Ibu administration (Figure 2).

\section{Epithelization and scar size of excision wound}

The control group animals took 17 days for reepithelization. These animals had a scar size of $4.5 \mathrm{sq} \mathrm{mm}$. Ibuprofen significantly $(P<.05)$ prolonged the period of epithelization by four days; besides the animals had bigger scar area than the control group of animals. The nitrooxyethyl-esterlinked ibuprofen not only reversed the healing-depressant propensity of ibuprofen on epithelialization, but also shortened the period of epithelialization by 3 days. The scar size in these animals was almost similar to that of control group animals (Table 3).

\section{Carrageenin-induced rat paw edema}

In carrageenin-induced rat paw edema, model of inflammation, NOE-Ibu showed similar antiinflammatory activity as compared to that of its parent drug, namely, ibuprofen (Table 4).

\section{Histopathological evaluation}

The length of the epithelial tongue from the wound margin in a control animal section was $772.5 \mu \mathrm{m}$. Besides, the section had fully grown dermis that was rich in collagen with 


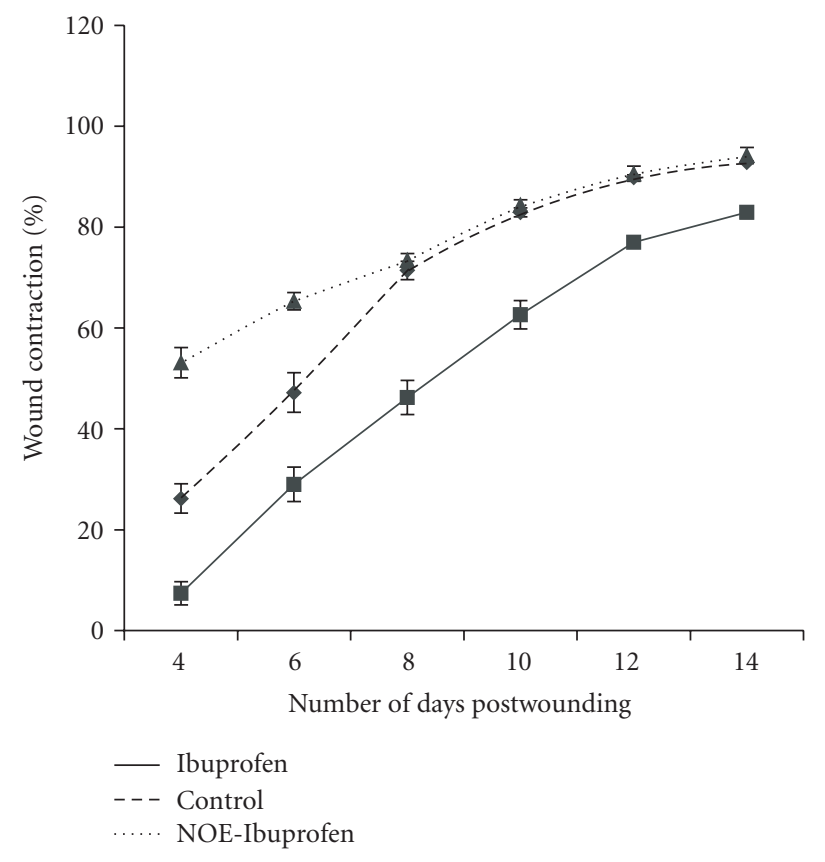

FIGURE 2: Effect of drugs on wound contraction. Contraction was studied by tracing the raw wound area on tracing paper on predetermined days, namely, days $4,6,8,10,12,14$, and 16 or till completion of healing, whichever was earlier. Ibuprofen group has significantly $(P<.05)$ lesser contraction than control group. NOE-ibuprofen has significantly $(P<.05)$ more contraction than ibuprofen.

TABLE 2: Effect of ibuprofen and its NOE on the granulation tissues of 10-day-old dead space wounds (by Scheffes test-SPSS computer package $)$. $(\mathrm{OHP}=$ orthohydroxyproline, $\mathrm{GSH}=$ reduced glutathione, TBARS $=$ thiobarbituric acid reactive species, $n=$ number of animals $)$. The difference between any two means is statistically significant if the mean difference is more than the allowance value calculated.

\begin{tabular}{lcccccc}
\hline Group $(n)$ & $\begin{array}{c}\text { Dose } \\
(\mathrm{mg} / \mathrm{kg})\end{array}$ & $\begin{array}{c}\text { Granulation breaking } \\
\text { strength }(\mathrm{g})\end{array}$ & $\begin{array}{c}\text { Dry granulation } \\
\text { weight }(\mathrm{g})\end{array}$ & $\begin{array}{c}\text { OHP } \\
\mathrm{mg} / \mathrm{g}\end{array}$ & $\begin{array}{c}\text { GSH } \\
(\mu \mathrm{g} / \mathrm{g})\end{array}$ & $\begin{array}{c}\text { TBARS } \\
(\mu \mathrm{M} / \mathrm{g})\end{array}$ \\
\hline Control (8) & - & $271 \pm 15.5$ & $32.6 \pm 3$ & $27.5 \pm 2.2$ & $7.08 \pm 1.30$ & $3.98 \pm 0.60$ \\
Ibuprofen (7) & 200 & $157 \pm 9.9^{a}$ & $16.3 \pm 2.1$ & $13.3 \pm 2.4^{a}$ & $34.87 \pm 5.44^{a}$ & $11.24 \pm 1.40^{a}$ \\
NOE-Ibu (7) & 300 & $403 \pm 12.4^{a, b}$ & $65.4 \pm 6.5^{a, b}$ & $43.4 \pm 3.2^{a, b}$ & $45.20 \pm 4.30^{a, b}$ & $2.25 \pm 0.20^{a, b}$ \\
\hline
\end{tabular}

$a=P<.05$ versus control.

$b=P<.05$ versus ibuprofen.

moderate number of inflammatory cells and blood vessels. A notable feature of Ibu section was that of a shorter-length epithelial tongue as compared to control, about $515 \mu \mathrm{m}$. Other features seen were fully grown dermis with poorly organized collagen. Except for the length of the epithelial tongue, all other features of NOE-Ibu-treated wound section were similar to that of control. The length of the epithelium in this case was $927 \mu \mathrm{m}$ (Figure 3).

\section{DISCUSSION}

Wound healing is a symphony of biological processes, initiated by tissue injury that culminates in restoration of tissue integrity. The end result of the repair process is fibrosis and scar in all organ systems except bone and specialized conditions of liver injury. Wound healing is the summation of a number of processes that follow injury; these include coagulation, inflammation, and matrix synthesis and deposition. These are followed by angiogenesis, fibroplasias, epithelialization, contraction, remodeling, and scar maturation. NSAIDs are one amongst such groups of agents that retard healing on their pre- and postsurgical administration to reduce pain and inflammation [1-3]. Different approaches have been made to overcome the negative effects of NSAIDs on healing without compromising their antiinflammatory and analgesic activities. For instance, zinc and copper have been linked coordinately with NSAIDs to develop coordinate compounds $[23,24]$. The present study is also aimed at that direction - the development of an NOENSAID. An idea worth contemplating stemmed from the findings that nitrooxyethyl derivatives (NO donors) and the NO that is released from the activated macrophages have a pivotal role in the pathophysiology of wound healing [25]. Besides this, some reports indicate that NOE-linked NSAIDs 
TABLE 3: Effect of ibuprofen and NOE-ibuprofen on epithelialization and scar size (by Scheffe's test-SPSS computer package). $(n=$ number of animals.) The difference between any two means is statistically significant if the mean difference is more than the allowance value calculated.

\begin{tabular}{cccc}
\hline Group $(n)$ & $\begin{array}{c}\text { Dose } \\
(\mathrm{mg} / \mathrm{kg})\end{array}$ & $\begin{array}{c}\text { Epithelization period (days) } \\
(\text { mean } \pm \text { SE })\end{array}$ & $\begin{array}{c}\text { Scar size }\left(\mathrm{mm}^{2}\right) \\
(\mathrm{mean} \pm \mathrm{SE})\end{array}$ \\
\hline Control (7) & - & $17.85 \pm 0.63$ & $4.57 \pm 0.48$ \\
Ibuprofen (7) & 200 & $22.66 \pm 1.08^{a}$ & $11.33 \pm 0.88^{a}$ \\
NOE-Ibu (7) & 300 & $14.71 \pm 0.42^{a, b}$ & $3.71 \pm 0.77^{b}$ \\
\hline
\end{tabular}

$a=P<.05$ versus control.

$b=P<.05$ versus ibuprofen.

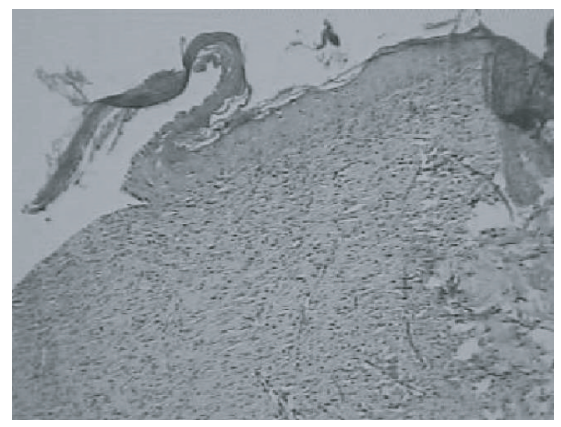

(a)

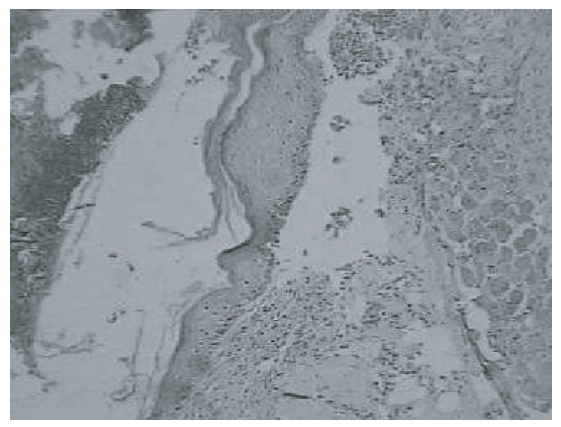

(b)

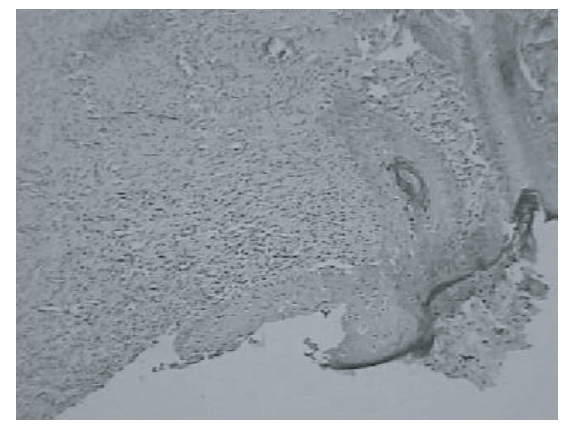

(c)

FIGURE 3: Photomicrograph showing granulation tissue interspersed with collagen $(\mathrm{H} \& \mathrm{E} \times 100)$ of (a) control group, of (b) ibuprofen group, and (c) treated with NOE-Ibu.

have better antiinflammatory activity and less gastric irritancy propensity than their parent NSAIDs [27]. Thus, in the present study nitrooxyethyl ester of ibuprofen was developed and compared with its parent compound for its influence on wound healing and inflammation.

Results of the study showed that the NOE-Ibu promoted collagenation (increase in breaking strength of skin and granulation tissue; increase in granulation weight and collagen content), wound contraction, and epithelialization phases of healing, while ibuprofen had healing-depressant propensity on all the phases of healing as compared to that of control. Antiinflammatory effect of NOE-Ibu in paw edema test was equivalent to that of ibuprofen.

Results of the study vindicated our assumption that linking of NO donors to ibuprofen would have prohealing activity. The macrophage is the one cell that is truly central to wound healing, serving to orchestrate the release of proinflammatory cytokines (TNF- $\alpha$, IL-1, IL-6, IL-8, INF$\gamma$ ), growth factors (PDGF, TGF- $\beta$, EGF, TGF- $\alpha$, FGF, IGF1 ), and other chemicals. One amongst them is NO. Nitric oxide activates angiogenesis, acts as a chemotactic to fibroblasts, and promotes fibroplasias [25]. All these may contribute to the promotion of collagenation phase of healing. Nitric oxide is known for its antioxidant potential. In our study, ibuprofen enhanced the MDA (marker of oxidative stress) levels in the granulation tissue, besides raising the GSH levels. The elevated GSH should have neutralized the oxidative stress that was induced by ibuprofen but it did not happen in this situation. Perhaps the levels of GSH in this case might not have been sufficient to do the same. In case of the treatment with NOE-Ibu, the level of MDA was reduced. This could perhaps be due to the result of a drastic rise in the levels of GSH and the presence of NO (antioxidant by itself) in the structures of NOE-Ibu. The antioxidant property of this molecule thus could also have contributed to the prohealing actions of this molecule. This assumption has got the basis that the oxidative stress is detrimental to the reparative process and some antioxidants are reported to have promoted the healing [17, 28, 29]. Beneficial effects of $\mathrm{NO}$ on wound repair may be attributed to its functional influence on angiogenesis, inflammation, cell proliferation, matrix deposition, and modulation of cytokine cascade.

However, it is very difficult to pinpoint the exact mechanism of the prohealing properties of NOE-Ibu, as the healing process is very complex and complicated involving many signaling pathways, chemicals, and so forth, that would link different phases of healing. Besides, some of the phases of healing such as wound contraction and epithelialization run concurrently and independently.

Whatever the mechanism of action of NOE-Ibu be, the prohealing action of the compound so identified through the present study may make this molecule very sound and promising in surgical wound management than its parent 
TABLE 4: Effect of ibuprofen and its NOE on carrageenin-induced rat paw edema (by Scheffe's test-SPSS computer package). $(n=$ number of animals.) The difference between any two means is statistically significant if the mean difference is more than the allowance value calculated.

\begin{tabular}{cccc}
\hline Group $(n)$ & $\begin{array}{c}\text { Dose } \\
(\mathrm{mg} / \mathrm{kg})\end{array}$ & $\begin{array}{c}\text { Edema volume }(\mathrm{mL}) \\
(\text { mean } \pm \text { SE) }\end{array}$ & $\begin{array}{c}\text { \% decrease in } \\
\text { edema volume }\end{array}$ \\
\hline Control $(8)$ & - & $0.40 \pm 0.009$ & \\
Ibuprofen (8) & 200 & $0.13 \pm 0.010^{a}$ & $66.5 \pm 2.67$ \\
NOE-Ibu (8) & 300 & $0.12 \pm 0.012^{a}$ & $69.37 \pm 3.08$ \\
\hline
\end{tabular}

$a=P<.05$ versus control.

drug. Pre- and postsurgical administration of NOE-Ibu would have the same antiinflammatory action and most importantly, it would not have the risk of healing impairment.

\section{REFERENCES}

[1] Lee KH. Studies on the mechanism of action of salicylate. II. Retardation of wound healing by aspirin. Journal of Pharmaceutical Sciences. 1968;57(6):1042-1043.

[2] Rao CM, Kumar A, Kulkarni DR. Effects of enfenamic acid and its zinc salt on wound-healing. Indian Journal of Physiology and Pharmacology. 1988;32(1):61-66.

[3] Kumar A, Rao M, Kulkarni DR. Zinc incorporation reverses suppressant effect of ibuprofen on wound healing. Indian Journal of Experimental Biology. 1988;26(6):483-485.

[4] Kulick MI, Smith S, Hadler K. Oral ibuprofen: evaluation of its effect on peritendinous adhesions and the breaking strength of a tenorrhaphy. Journal of Hand Surgery. 1986;11(1):110-120.

[5] Dvivedi S, Tiwari SM, Sharma A. Effect of ibuprofen and diclofenac sodium on experimental wound healing. Indian Journal of Experimental Biology. 1997;35(11):1243-1245.

[6] Dong Y-L, Fleming RYD, Yan TZ, Herndon DN, Waymack JP. Effect of ibuprofen on the inflammatory response to surgical wounds. Journal of Trauma. 1993;35(3):340-343.

[7] Mloliane E, Whittle B, Moncada S. Nitric Oxide as a factor in inflammation. In: Inflammation Basic Principles and Clinical Correlates. 3rd ed. Philadelphia, Pa: Lippincott Williams \& Wilkins; 1999:787-795.

[8] Masini E, Salvemini D, Pistelli A, Mannaioni PF, Vane JR. Rat mast cells synthesize a nitric oxide like-factor which modulates the release of histamine. Agents and Actions. 1991;33(1-2):6164.

[9] Masini E, Di Bello MG, Pistelli A, et al. Generation of nitric oxide from nitrovasodilators modulates the release of histamine from mast cells. Journal of Physiology and Pharmacology. 1994;45(1):41-53.

[10] Coleman JW. Nitric oxide: a regulator of mast cell activation and mast cell-mediated inflammation. Clinical and Experimental Immunology. 2002;129(1):4-10.

[11] Salvemini D, Wang Z-Q, Wyatt PS, et al. Nitric oxide: a key mediator in the early and late phase of carrageenaninduced rat paw inflammation. British Journal of Pharmacology. 1996;118(4):829-838.

[12] Salvemini D, Seibert K, Masferrer JL, Settle SL, Currie MG, Needleman P. Nitric oxide activates the cyclooxygenase pathway in inflammation. American Journal of Therapeutics. 1995;2(9):616-619.

[13] Salvemini D, Misko TP, Masferrer JL, Seibert K, Currie MG, Needleman P. Nitric oxide activates cyclooxygenase enzymes.
Proceedings of the National Academy of Sciences of the United States of America. 1993;90(15):7240-7244.

[14] Ziche M, Morbidelli L. Nitric oxide and angiogenesis. Journal of Neuro-Oncology. 2000;50(1-2):139-148.

[15] Wang L, Kubodera S, Araki I, Takihana Y, Ueno A, Takeda M. Inhibition of nitric oxide synthase induces intestinal mucosal damage and increases mortality in rats treated by FK506. Experimental and Toxicologic Pathology. 2001;53(4):297-301.

[16] Capasso F, Mascolo N, Izzo AA, Gaginella TS. Dissociation of castor oil-induced diarrhoea and intestinal mucosal injury in rat: effect of NG-nitro-L-arginine methyl ester. British Journal of Pharmacology. 1994;113(4):1127-1130.

[17] Luo J-D, Chen AF. Nitric oxide: a newly discovered function on wound healing. Acta Pharmacologica Sinica. 2005;26(3): 259-264.

[18] Cooke JP. NO and angiogenesis. Atherosclerosis Supplements. 2003;4(4):53-60.

[19] Wallace JL. Nitric oxide as a regulator of inflammatory processes. Memorias do Instituto Oswaldo Cruz. 2005;100(suppl 1):5-9. Epub 2005 June 14.

[20] Ehrlich HP, Hunt TK. The effects of cortisone and anabolic steroids on the tensile strength of healing wounds. Annals of Surgery. 1969;170(2):203-206.

[21] Ehrlich HP, Hunt TK. Effects of cortisone and vitamin A on wound healing. Annals of Surgery. 1968;167(3):324-328.

[22] Ehrlich HP, Tarver H, Hunt TK. Inhibitory effects of vitamin E on collagen synthesis and wound repair. Annals of Surgery. 1972;175(2):235-240.

[23] Patil PA, Kulkarni DR. Effect of antiproliferative agents on healing of dead space wounds in rats. Indian Journal of Medical Research. 1984;79(3):445-447.

[24] Kumar A, Rao CM, Kulkarni DR. Zinc incorporation reverses suppressant effect of ibuprofen on wound healing. Indian Journal of Experimental Biology. 1988;26(6):483-485.

[25] Somayaji SN, Bairy KL. Effect of enfenamic acid and its copper complex on wound healing. Indian Drugs. 1997;34(9):493496.

[26] Herrmann JB, Woodward SC. Stimulation of fibroplasia by vitamin A. Surgical Forum. 1969;20:500-501.

[27] Ohkawa H, Ohishi N, Yagi K. Assay for lipid peroxides in animal tissues by thiobarbituric acid reaction. Analytical Biochemistry. 1979;95(2):351-358.

[28] Wallace JL, Cirino G. The development of gastrointestinalsparing nonsteroidal anti-inflammatory drugs. Trends in Pharmacological Sciences. 1994;15(11):405-406.

[29] Dissemond J, Goos M, Wagner SN. The role of oxidative stress in the pathogenesis and therapy of chronic wounds [Die Bedeutung von oxidativem Stress in der Genese und Therapie chronischer Wunden]. Der Hautarzt. 2002;53(11):718-723. 


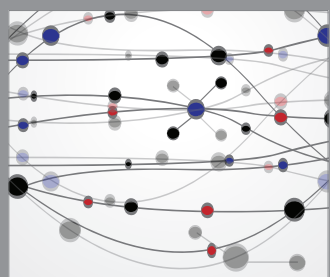

The Scientific World Journal
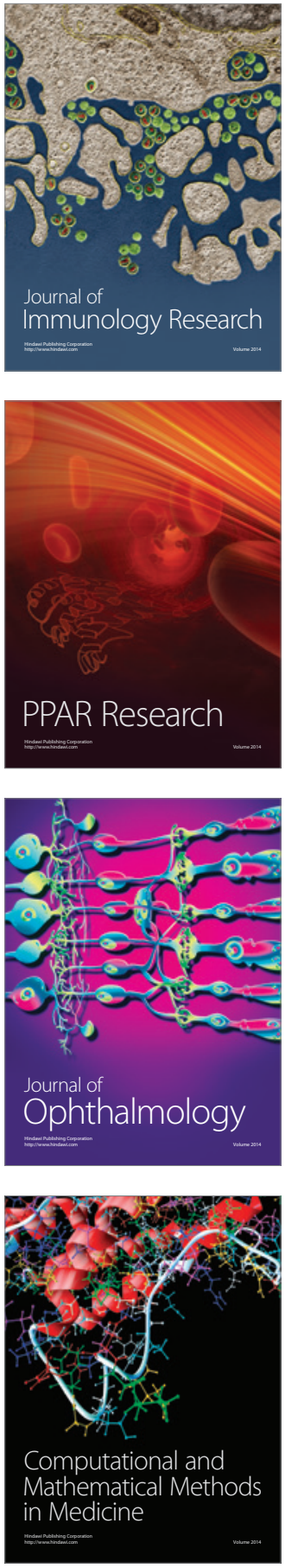

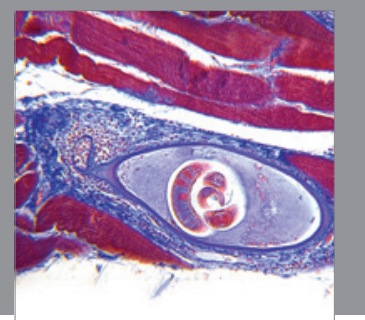

Gastroenterology

Research and Practice
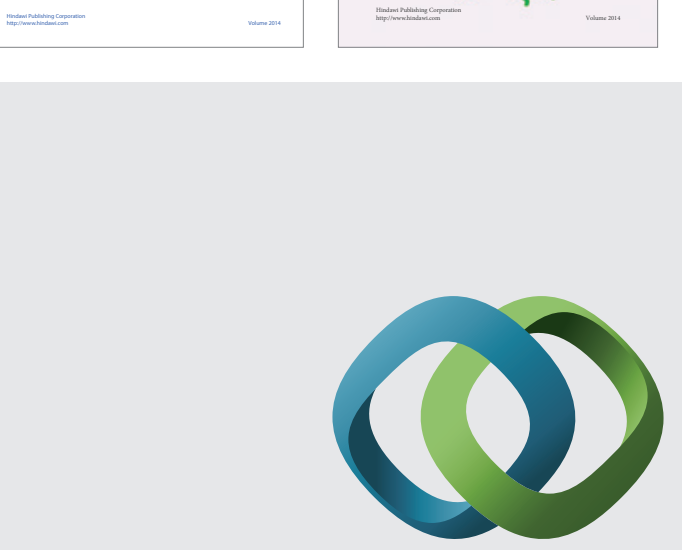

\section{Hindawi}

Submit your manuscripts at

http://www.hindawi.com
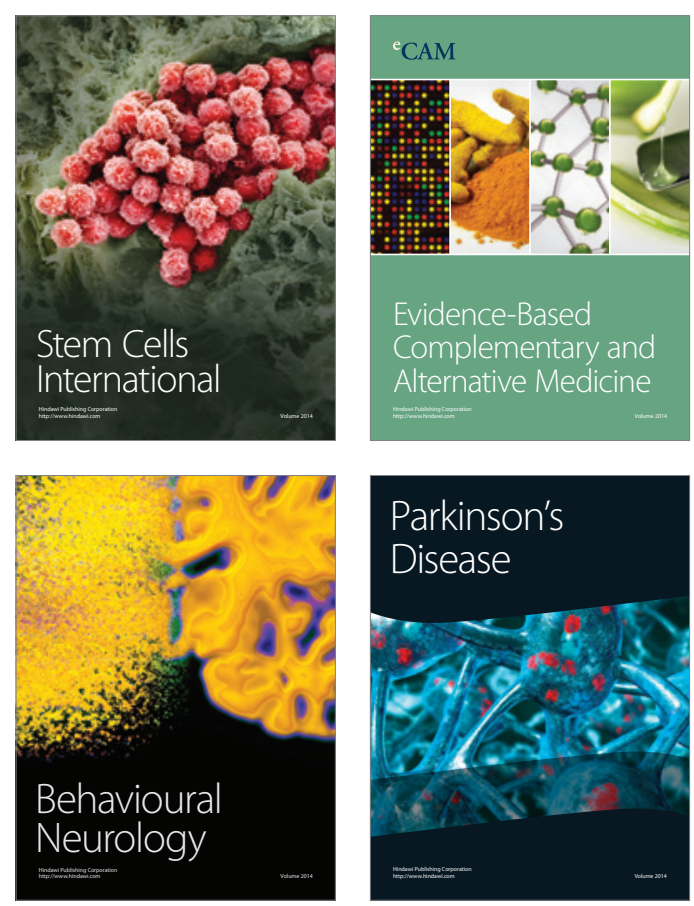

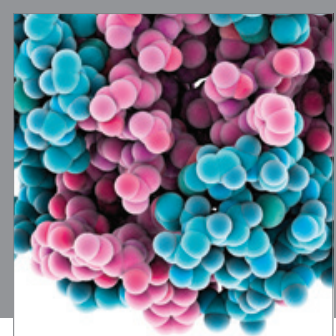

Journal of
Diabetes Research

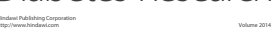

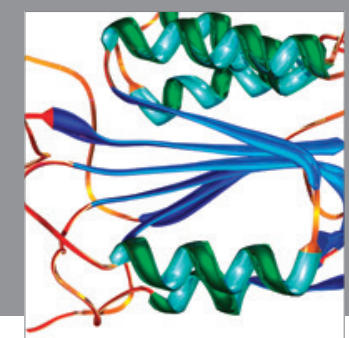

Disease Markers
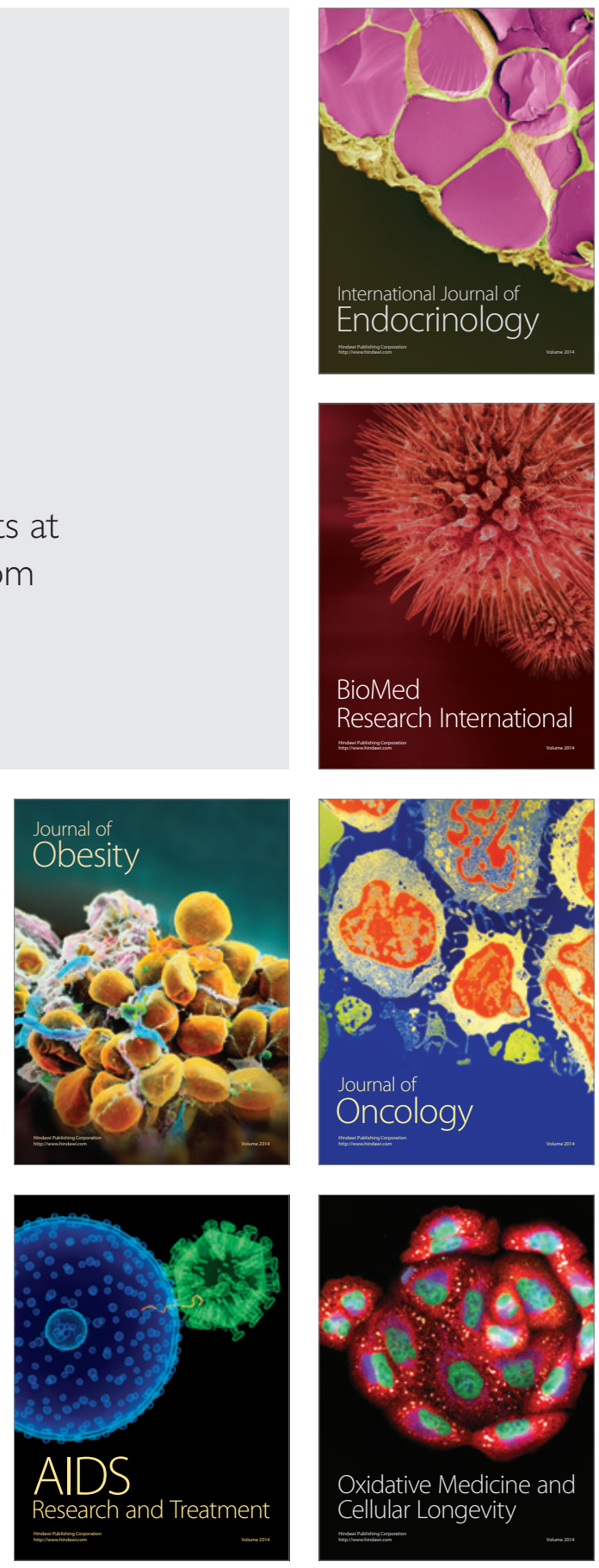